Brit. F. vener. Dis. (1970) 46, 159

\title{
Forward planning in the United Kingdom for anti-V.D. education
}

\author{
A. J. DALZELL-WARD \\ Health Education Council, London
}

AN analysis of the general problem of anti-V.D. education suggests that there are five main parts:

(1) Identification of special risk groups;

(2) Ignorance of young people regarding V.D.;

(3) Attitudes, both of those who are at risk, and of the community generally;

(4) Means of influencing behaviour;

(5) Methodology.

Extensive research has been conducted in the United Kingdom in order to find clues for a more effective approach. The idea that health education and the influencing of personal behaviour are important in venereal disease control is well established. It was implicit in the text of the Public Health (Venereal Diseases) Act of 1916 which recommended that local authorities should organize schemes of public instruction to educate the public about the dangers of venereal diseases, how they are acquired and spread. This legislation was enacted in the early years of the first world war and can be regarded as an example of the recognition of a high risk group-in this case, young people in the armed services and in civil life, whose lives were disturbed by war.

Although early attempts at education of the public regarding venereal diseases were based entirely upon communication of facts-regarding pathology, epidemiology, and treatment-modern developments in health education, drawing attention to the importance of behavioural concepts, have resulted in there being an almost unanimous opinion that an effective approach must be based upon research into levels of knowledge, attitude, and social and environmental circumstances influencing behaviour.

Schofield (1965) was commissioned by the Central Council for Health Education to investigate the sexual behaviour of boys and girls aged between 15 and 19 years. This research project had the support of the British Federation against the Venereal Diseases and was inspired by the work of that body which, from its inception, has been interested in the social and behavioural aspects. The identification of a personality profile which was significantly associated with sexual promiscuity is the finding relevant to this paper. Sexually experienced boys and girls differed significantly from those who were not experienced and, characteristically, tended to be alienated from home ties, to be deprived of or, perhaps, resisting parental affection, and to believe that members of their age group were unique in the community, not only with special needs but with special rules applying to their conduct.

It was now possible to isolate a special risk group within an age group which is generally at higher risk of venereal infection than others. This finding emphasizes the futility of making a general approach on a basis which may be considered appropriate by professional people, who draft and communicate the message, but which is inappropriate to the age group as a whole, or to the subgroup which our research findings show to be one at special risk. It was found that there was a general lack of knowledge about the nature of venereal diseases and the way in which they are contracted. The conclusion was that, if these young people had been suffering from venereal disease, then they would not have been able to recognize the symptoms.

More recently, Holmes, Nicol, and Stubbs (1969) conducted a survey of attitudes to sex and to sex education with a group of 152 young people attending a V.D. Clinic in a large London hospital. These young people came from all strata of society and from mainly normal home backgrounds. 68 per cent. thought that they got on well with their parents, but rather more of them lived away from home and rather fewer of them had parents who wanted to know where they were, than a general cross-section of young people of the same age group in the same area of London. Only 5 per cent. of the sample had attended grammar schools-that is schools offering higher education possibly leading to a professional career-compared with the 23 per cent. of the same age group in the area of the same Education Authority. 43 per cent. of the sample had left school at the minimum statutory age compared with only 23 per cent. for the rest of the area. 
One of the purposes of this survey was to find out what kind of sex education these young people had experienced and what kind of instruction they would have liked to have had at school. The majority said that they would have liked to have had more sex education at school and claimed that their parents were too embarrassed to discuss sex with them. A number said that sex education should begin in the primary school-that is before the age of 11 years. In this respect, it is interesting to observe that an increasing number of Local Education Authorities in the United Kingdom are giving serious consideration to starting sex education at this early age.

As regards the kind of person who should do the teaching, it was not considered that a medicallyqualified person was necessary but they felt that the teacher should be unembarrassed and should allow the class to discuss questions freely. Most significantly, the majority felt that sex-education should be given in the context of a normal part of life-not merely as an insurance against the dangers of venereal disease and unwanted pregnancy. There was a general feeling that simple instruction was not enough and opportunities for discussion were requested.

Hollins and Dicks (1968), however, working in secondary schools in the County of Wiltshire, found that whereas grammar school pupils preferred discussion to straightforward talks and the showing of films, pupils in other kinds of secondary schoolthat is those who were not likely to proceed to higher education-seemed to prefer didactic instruction. They found, however, that amongst the latter a debate was acceptable. This is a method of discussion that has, hitherto, not been considered in the field of health education.

During the last few years several schemes have been established, with the general title 'Education for Personal Relationships'. This reflects the opinion in the United Kingdom that sex education and education regarding venereal disease cannot be considered apart from education for mental health and personal relationships. A typical scheme provides an integrated programme for schoolchildren from the age of 11 until they leave school at 15, 16, 17 or 18 , according to the type of school. The subject of venereal diseases is included in this programme and is dealt with in the final year at school, but only after a thorough grounding in the biology and sociology of all matters concerned with human sex, reproduction, and family life. A simple approach to psychodynamics and sociology is included-for example, there is discussion on cruelty, and this is relevant to earlier findings that promis- cuity is associated with personalities in which sexuality and affection are separated.

It is interesting to examine the kind of question that emerges from the pupils in the course of sessions on venereal disease. Typical questions are:

(1) Please explain the various forms of V.D.

(2) How is V.D. contracted?

(3) What are the symptoms?

(4) What is the cure for V.D.?

It is found that girls are particularly concerned about the effects of V.D. on the unborn child, and this question is invariably put to visiting lecturers.

In the United Kingdom the health education of young people in respect of venereal diseases is receiving an increasing contribution from the mass media, encouraged by the generally permissive atmosphere with regard to the public discussion of sex. The subject is discussed freely on television and radio and is becoming a subject in which popular journalists are increasingly interested. Magazines for teenagers, particularly those for girls, now frequently carry well-informed, instructive, and optimistic articles. The exhibition of posters on the subject of V.D. presents the problem of expense, as few poster sites are available other than those which are free to Local Health Authorities. It is difficult, therefore, to measure the effect of posters, as this restriction on exhibition has obviously detracted from their effectiveness, but in the general climate of public opinion at present-if money were forthcomingthere could be a widespread distribution of posters.

With regard to forward planning, the Health Education Council has already embarked on a research project designed to test the reaction of a group of teenagers to a film entitled 'A Quarter of a Million Teenagers' from the standpoints of:

(1) Communication of essential information about the contraction and effects of venereal diseases.

(2) Comprehension of certain aspects of venereal diseases.

(3) The reactions of the audience to this treatment of the subject matter, in specific and general terms.

A test was conducted with the co-operation of 233 boys and girls, aged 13-15, recruited from the Greater London Area. The film was screened under strictly controlled conditions and immediately after the showing a series of specially-designed questions was administered-again under controlled conditions. The parents and guardians of these children accompanied them to the showing and afterwards, separately from their charges, answered questions designed to assess the reaction to the film and its implications, from the parents' point of view.

The results have been classified according to the initial reactions, the communication of facts and ideas, and other aspects of reaction and understand- 
ing. Under this general heading are included the opinions of the viewers regarding the design and quality of the film, the effectiveness of diagrams and animation, the effect of the commentary, and whether the showing of photographs of infected people was approved. It was also ascertained whether any aspects of the film were 'upsetting'.

The findings, which are extensive and which have been reached by an elaborate analytical procedure, will eventually be published in full. It may be said at this stage, however, that it has been possible to ascertain whether a film on venereal disease can encourage young people to seek treatment if they have symptoms, or whether it is likely to have adverse effects through malcommunication.

As regards the communication of facts and ideas, the initial results showed that it is possible to test the effectiveness in communicating accurate ideas about anatomy, physiology, and pathology, and in teaching correct terminology. The testing procedure adopted was to show a number of 'stills' from the film, in which questions were asked as to the exact meaning of a diagram or picture.

A parental evaluation of the film's suitability for 13-15 year olds showed that, of 207 adults, 88 per cent. considered it to be suitable and only four not suitable, the remainder being unsure or, in one case, not answering at all. A small majority of the adults - 55 per cent.-considered that more should be included in the content of the film and their replies indicated that their opinions ranged from the need for emphasis on moral principles to giving a list of local V.D. Clinics in the area in which the film was shown. Their views regarding omissions showed a very wide scatter-some opinions being expressed only by single individuals and the largest percentage of agreement being no more than 24 per cent. This was in the case of the need for more detailed explanation of how V.D. is caught. Asked whether they thought it was right to have this kind of film shown to children in school, 93 per cent. of parents declared that they believed it to be a good thing.

The Health Education Council, which took over the work of The Central Council for Health Education in 1968, will take a close interest in research into health education in all fields. The type of project which I have described will form a substantial part of our work and we have the advice of an Honorary Research Adviser in Methodology of Communication Research and the technical assistance of skilled research agencies. It is proposed to test all materials that are used in health education-posters, leaflets, films, slides, etc. - with a view to making them more effective. We feel the need in the United Kingdom for a new film on venereal diseases, but we are reluctant to embark on what can be an expensive venture without the necessary background of research.
The opinion of the majority in the United Kingdom is that the problem of venereal diseases is one facet of the problem of sexual promiscuity, which is, in its turn, a facet of the problem of mental health and human relations. Part of our forward planning, therefore, is the overall promotion and improvement of education in personal relationships, emphasizing personal responsibility. Teachers are taking an active interest in this matter and the In-service Training Programme of the Health Education Council includes numbers of sessions and seminars for teachers, at which this subject is discussed. The extension to Great Britain of the work of the International Federation for Parent Education, given prominence by the holding of an International Conference at Leeds in April, 1969, will also strengthen the general programme for the promotion of mental health in the family. The close association between family ties and the quality of family relationships, and the motivational factors that may lead to a promiscuous life, are now well-established, and the time has come to apply these directly to education.

In this field, also, further research will be necessary. It will be important, for example, to find out whether there is a normal curve of sexual activity in which individuals vary in their sexual drive, as they vary in other biological characteristcs. If this is the case, then we have to accept as biologically inescapable the existence of a high-risk group at the top end of the normal curve. If, on the other hand, differences in sexual activity and drive are socially conditioned, then we have further measures, not for prevention-which is perhaps an inappropriate word in this context-but for the promotion of the optimum handling of the sex instinct. Some of the research we have conducted already suggests that the level of personal and social values is a factor, particularly in the case of the notorious double standard of conduct, and we now have material which can be used in discussion with senior pupils in schools, so that they can come to terms with their own motivations and make a decision as to their personal responsibility.

In this work we shall bring together a number of professional disciplines which, together, can fashion a new educational policy based on sound scientific principles, rather than upon empiricism or the mere arbitrary application of personal judgement.

\section{References}

Holins, F. R., and Dicks, S. (1968). Med. Offr, 120, 261.

Holmes, M., Nicol, C., and StubBs, R. (1969). Hlth Educ. F., 28, 13.

Schofield, M. G. (1965). 'The Sexual Behaviour of Young People'. Longmans, London. 